\title{
Shaking Water Bath Berbasis Mikrokontroler Atmega 16
}

\author{
Sumardi*1, Bambang Untara ${ }^{2}$ \\ ${ }^{1}$ Universitas Muhammadiyah Yogyakarta, Indonesia \\ ${ }^{2}$ RSUP Dr. Sardjito Yogyakarta, Indonesia
}

INFO ARTIKEL

Alamat Web Artikel:

https://journal.umy.ac.id/index.php $/ \mathrm{mt} /$ article/view/7322

DOI:

https://doi.org/10.18196/mt.020114

Data Artikel:

Diterima:

26 Oktober 2019

Direview:

13 November 2019

Direvisi:

07 Desember 2019

Disetujui:

07 April 2020

Korespondensi: sumardi.2016@vokasi.umy .ac.id

\begin{abstract}
ABSTRAK
Shaking Water Bath merupakan alat yang digunakan untuk proses pemanasan atau inkubasi sampel larutan sekaligus pencampuran. Shaking Water Bath yang digunakan selama ini masih memiliki sistem pembuangan air manual sehingga harus membalik alat untuk membuang air dan ada kemungkinan akan terkena air panas. Oleh karena itu dirancang alat Shaking Water Bath yang dapat melakukan pengisian dan pembuangan air secara otomatis. Perancangan alat ini menggunakan heater basah sebagai pemanas air pada chamber dan suhu pada chamber akan dideteksi oleh sensor LM35. Nilai suhu yang dideteksi oleh sensor LM35 akan ditampilkan pada LCD karakter $4 \times 20$. Alat yang dirancang ini juga dilengkapi dengan sistem pengisian dan pembuangan air secara otomatis melalui solenoid valve yang dikendalikan oleh mikrokontroler. Pengujian dilakukan dengan cara membandingkan nilai yang ditampilkan pada LCD dengan alat ukur stopwatch untuk parameter timer dan termometer untuk parameter suhu. Pengambilan data untuk timer dan suhu dilakukan sebanyak 20 kali dan pengujian pencampuran dilakukan sebanyak 3 kali pengujian dengan bahan yang berbeda. Berdasarkan hasil pengukuran pada pengujian timer dan suhu didapat nilai error sebesar 0,017 \% pada pengujian timer 5 menit, 0,22 \% pada timer 10 menit, $0,13 \%$ pada timer 15 menit, $0,38 \%$ pada pengujian suhu $37{ }^{\circ} \mathrm{C}$, $0,22 \%$ pada suhu $45{ }^{\circ} \mathrm{C}$, dan $0,37 \%$ pada suhu $55^{\circ} \mathrm{C}$. Hasil pengujian pencampuran dan pembuangan air didapat bahwa alat dapat melakukan pencampuran 2 bahan dan alat dapat melakukan pembuangan air secara otomatis sesuai setting pada program. Berdasarkan data hasil pengujian, maka dapat disimpulkan bahwa alat "Shaking Water Bath" ini dapat bekerja dengan baik dan layak untuk digunakan.
\end{abstract}

Kata Kunci: Pembuangan dan Pengisian Air Otomatis, Shaking Water Bath, Suhu

\begin{abstract}
Shaking Water Bath is a tool for heating or incubating solutions samples as well as mixing. The Shaking Water Bath that has been used so far still has a manual drainage system, so you have to turn the device over to remove the water, and possibly the hot water spilled out. Thus, a Shaking Water Bath tool is designed to fill and drain water automatically. The design of this tool uses a wet heater as a water heater in the chamber, and the LM35 sensor will detect the temperature in the chamber. Consequently, the temperature value detected by the LM35 sensor will be displayed on the $4 \times 20$ LCD. Additionally, the tool is also equipped with a water filling and discharging system automatically through a solenoid valve controlled by a microcontroller. The test was carried out by comparing the value displayed on the LCD with a stopwatch measuring instrument for the timer parameter and a thermometer for the temperature parameter. Data collection for the timer and temperature was carried out 20 times while mixing testing was carried out three times with different materials. Based on the measurement results on the timer and temperature testing, the error value was $0.017 \%$ on the 5 -minute timer test, $0.22 \%$ on the 10 -minute timer, $0.13 \%$ on the 15 -minute timer, $0.38 \%$ at $37^{\circ} \mathrm{C}, 0.22 \%$ at $45^{\circ} \mathrm{C}$, and $0.37 \%$ at $55^{\circ} \mathrm{C}$. The results of the mixing and water disposal test showed that the tool could mix two ingredients and discharge water automatically according to the settings. Based on the test data, the "Shaking Water Bath" tool can work well and is suitable for use.
\end{abstract}

Keywords: Automatic Water Filling and Disposal, Shaking Water Bath, Temperature 


\section{PENDAHULUAN}

Hematologi adalah cabang ilmu kedokteran yang mempelajari kondisi normal dan patologis darah yang meliputi struktur darah, komponen darah, fungsi darah dan pembuluh darah. Pemeriksaan hematologi adalah pemeriksaan yang dilakukan untuk mengetahui keadaan darah dan komponen-komponennya. Selain itu, dapat juga dilakukan pemeriksaan Activated Partial Thromboplastin Time (APTT), Plasma Thromboplastin Time (PTT), dan International Normalizer Ratio (INR) yang bertujuan untuk menilai pembekuan darah dan gangguannya [1].

Alat yang ada di laboratorium hematologi untuk proses pencampuran sampel antara lain magnetik stirer, incubator shaker, roler mixer, dan shaking water bath. Pemeriksaan PT, APTT dan INR pada laboratorium Hematologi dapat diproses menggunakan alat incubator shaker atau shaking water bath dengan sampel yang digunakan berupa plasma, yaitu bagian cairan darah yang berwarna kekuningan [1].

Shaking water bath merupakan alat untuk menghasilkan suhu air yang konstan selama waktu yang telah ditentukan dan ditambahkan fungsi penggerak untuk menggoyang sample, sehingga memberikan aspek metabolisme mikroba. Secara umum berdasar suhu lingkungan tempatnya hidup mikroba dikelompokan menjadi 3 kelompok yaitu psikrofil yang dapat hidup pada suhu $0{ }^{\circ} \mathrm{C}-25$ ${ }^{\circ} \mathrm{C}$, mesofil yang dapat hidup pada suhu $20^{\circ} \mathrm{C}-50^{\circ} \mathrm{C}$, dan termofil yang dapat hidup pada suhu 45 ${ }^{\circ} \mathrm{C}-80^{\circ} \mathrm{C}$ [2]. Sehingga dalam aplikasinya di laboratorium, water bath biasanya digunakan untuk proses pemanasan sampel dengan suhu yang relatif rendah $30^{\circ} \mathrm{C}$ sampai $80^{\circ} \mathrm{C}$.

Alat shaking water bath tidak banyak diproduksi di Indonesia, sehingga untuk keperluan laboratorium di Indonesia alat shaking water bath dibeli ke luar negeri (Jerman, Amerika dan China) [3]. Alat yang harus dibeli dari luar negeri ini mengakibatkan ketersediaan alat di beberapa laboratorium Indonesia sangat minim.

Akibat minimnya alat shaking water bath di laboratorium Indonesia, sehingga beberapa peneliti mengembangkan alat water bath di antaranya Ahmad Amir Amzaili, membuat water bath dengan kontrol pembuangan air otomatis. Peneliti ini hanya mengontrol suhu pada alat water bath dan alat yang dirancang belum memiliki shaking[4].

Pada tahun 2015 Ridha Khairani Program Studi Fisika Pascasarjana FMIPA Universitas Andalas melakukan penelitian dengan judul Rancang Bangun Sistem Kontrol Solution Shaker Berbasis Mikrokontroler At89S51 Dengan Motor Steper Sebagai Penggerak. Pada rancang bangun ini bertujuan mencampur larutan di laboratorium menggunakan sebuah wadah yang terbuat dari akrilik yang digerakan ke kanan dan ke kiri menggunakan motor stepper, sehingga larutan akan tercampur. Pada alat ini kecepatan putaran motornya tidak dapat diatur (konstan) [3].

Pada tahun 2016 telah dilakukan penelitian oleh Agus Prihartono dan Dwi Larassati dari Puslit Metrologi LIPI, Tangerang, Banten dengan judul Perancangan dan Pembuatan Sistem Otomatis Water Bath untuk kalibrasi suhu. Tujuan pembuatan alat ini yaitu output dari suhu water bath digunakan untuk kalibrasi suhu termometer yang dapat dijalankan secara otomatis. Namun pada alat ini untuk pembuangan air pada water bath masih dilakukan manual [5].

Pada tahun 2017 Khairiati dan Wildian Jurusan Fisika, Universitas Andalas melakukan penelitian dengan judul Rancang Bangun Shaking Water Bath Berbasis Mikrokontroler Atmega 16. Rancangan alat ini dirancang dengan harga murah dan dapat mengendalikan suhu, waktu dan laju putaran motor. Rancangan alat ini menggunakan motor AC yang dilengkapi dengan sensor suhu dan elemen pemanas air. Namun rancangan alat ini untuk pembuangan air pada water bath masih dilakukan secara manual belum otomatis [6].

Pada tahun 2018 Irfan Sandy Jurusan Teknik Elektromedik Poltekes Kemenkes Jakarta II merancang Rancang Bangun Inkubator Shaker berbasis Arduino. Alat yang dirancang digunakan untuk mempertahankan kondisi darah dengan menstabilkan suhu dan gerakan agar sampel darah tidak mengalami penggumpalan dan pembekuan. Agar darah tidak rusak, maka suhu pada darah harus stabil $37{ }^{\circ} \mathrm{C}$ sesuai suhu tubuh manusia normal. Untuk kecepatan motor inkubator shaker yang dirancang terdiri dari tiga kecepatan yaitu kecepatan rendah $100 \mathrm{rpm}$, kecepatan sedang 200 rpm, dan kecepatan tinggi $300 \mathrm{rpm}$. Untuk suhu pada alat yang dirancang ini tidak dapat dirubah, hanya berfokus pada suhu $37^{\circ} \mathrm{C}[7]$.

Medika Teknika : Jurnal Teknik Elektromedik Indonesia, Vol 02 No. 1, Oktober 2020|28 


\section{Sumardi, Untara}

Shaking Water Bath Berbasis Mikrokontroler Atmega16

Pembuangan air secara manual pada water bath dinilai kurang efektif dan bisa menimbulkan resiko bagi tenaga medis. Saat membuang atau menguras air pada water bath yang kondisi airnya masih panas bisa mengakibatkan tenaga medis terkena tumpahan air panas dari alat tersebut, dan jika harus menunggu air didalam waterbath dingin, maka membutuhkan waktu yang lama dan kurang efektif. Oleh karena itu perlu dirancang pembuangan air secara otomatis agar lebih efektif dan untuk menghindari resiko pada tenaga medis sehingga lebih aman.

Berdasarkan dari penelitian yang telah dilakukan diatas, maka dalam penelitian ini akan dirancang alat shaking water bath yang dapat mengontrol suhu, mengontrol waktu dan pilihan laju shaking. Rancangan alat ini dibuat menggunakan motor DC (Direct Current) yang dilengkapi dengan sensor suhu, dan elemen pemanas air. Penggunaan motor DC dikarenakan motor DC sebagai pengendali kecepatan tidak mempengaruhi kualitas pasokan daya. Agar pengguna tidak kerepotan mengisi dan membuang air pada water bath, maka di alat ini juga dilengkapi sistem pengisian dan pembuangan air secara otomatis dengan memanfaatkan kerja valve yang dikendalikan oleh mikrokontroler.

\section{METODE PENELITIAN}

Metode yang dilakukan dalam penelitian ini terdiri dari beberapa tahap, yaitu: perancangan hardware, perancangan software, perancangan desain alat, dan pengambilan data pengujian alat.

\subsection{Perancangan Hardware}

Pada perancangan alat, akan dirancang sebuah skematik rangkaian elektronika secara keseluruhan yang ditunjukkan pada Gambar 1 dibawah ini.

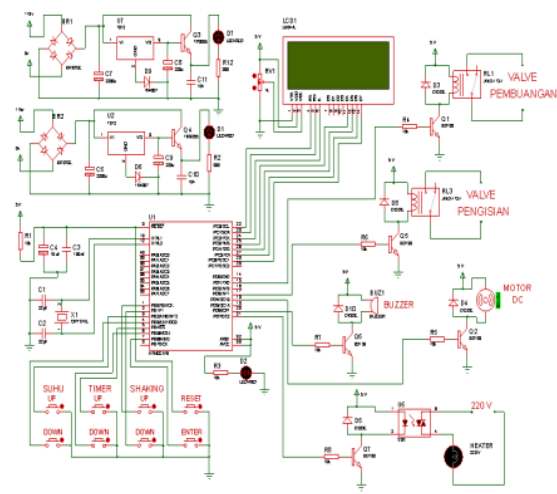

Gambar 1. Rangkaian Keseluruhan shaking water bath

Power supply akan men-supply tegangan ke mikrokontroler dan ke semua rangkaian driver. Rangkaian push button digunakan sebagai tombol control pengaturan suhu, timer, putaran motor dan start serta untuk mereset proses bekerjanya alat. Mikrokontroler akan memproses semua pengaturan yang dimasukan oleh pengguna alat. Setelah semua pengaturan diproses, maka akan diteruskan ke driver.

Driver valve tersambung ke PIN D1 dan D3 sebagai pengendali valve pembuangan dan pengisian air. Driver heater tersambung ke PIN D7 sebagai pengendali heater untuk memanaskan air. Driver motor tersambung ke PIN D4 sebagai pengendali motor untuk menggoyang sampel. Driver buzzer tersambung ke PIN D6 sebagai pengendali buzzer untuk memberi tanda bahwa proses selesai.

\subsubsection{Rangkaian Catu Daya}

Catu daya merupakan sebuah supply listrik yang digunakan untuk menyalakan sebuah peralatan elektronik. Tanpa catu daya peralatan elektronik tidak akan bisa digunakan, pada perancangan alat ini digunakan tegangan PLN 220V AC yang nantinya akan diturunkan dan disearahkan pada rangkaian power supply, Pada rangkaian power supply ini menggunakan beberapa komponen antara lain trafo step down CT, 2 buah diode bridge 2 A, 2 buah kapaitor 220

Medika Teknika : Jurnal Teknik Elektromedik Indonesia, Vol 02 No. 1, Oktober 2020|29 


\section{Sumardi, Untara}

Shaking Water Bath Berbasis Mikrokontroler Atmega16

$\mu \mathrm{F}, 2$ buah kapasitor $2200 \mu \mathrm{F}$, dan 1 buah IC regulator 7805 dan 7812 untuk menghasilkan keluaran $5 \mathrm{~V}$ DC dan $12 \mathrm{~V}$ DC, serta 2 buah LED sebagai lampu indikator.

Adapun komponen diode bridge berfungsi untuk menyearahkan tegangan listrik yang akan diteruskan pada komponen kapasitor yang berfungsi sebagai isolator, dan adapun komponen IC regulator 7805 yang berfungsi untuk mempertahankan suatu tegangan pada level tertentu secara otomatis sehingga akan menghasilkan pengeluaran tegangan sebesar $5 \mathrm{~V}$ DC yang nantinya akan disalurkan pada rangkaian minimum sistem dan rangkaian buzzer, sedangkan IC 7812 digunakan untuk menghidupkan valve dan motor DC. Skematik power supply alat ini ditunjukkan pada Gambar 2 dibawah ini.

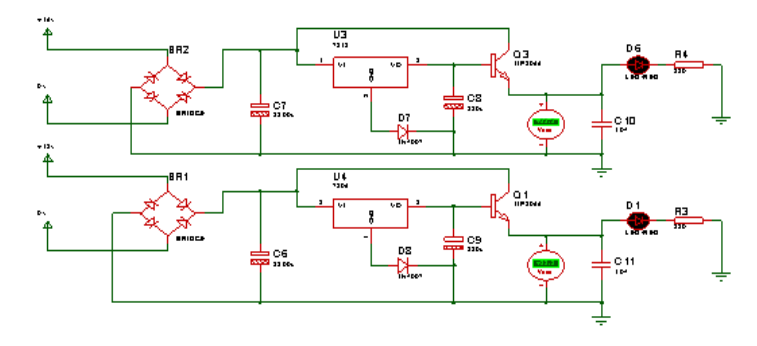

Gambar 2. Rangkaian Power Supply

\subsubsection{Rangkaian Minimum Sistem ATMega 16}

Rangkaian minimum sistem merupakan pusat pengendali yang akan mengendalikan kerja setiap blok hardware yang terintegrasi pada minimum sistem tersebut. Minimum sistem adalah sebuah otak dalam suatu alat, dimana tanpa otak tersebut maka alat tidak dapat bekerja dengan baik. Dengan adanya minimum sistem ini, suatu sistem kendali dapat tercipta dengan sederhana dan efisien dikarenakan sistem kendali dirancang dengan bahasa pemograman yang ditanam dalam IC ATMega 16. Pada perancangan alat ini menggunakan basis mikrokontroler ATMega 16, adapun rangkaian skematik minimum sistem ATMega 16 ditunjukkan pada Gambar 3 dibawah ini.

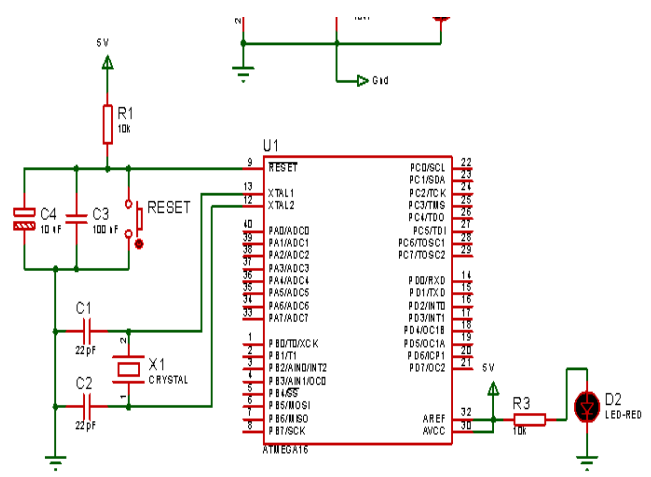

Gambar 3. Rangkaian Minimum Sistem

Minimum sistem dibuat menggunakan IC mikrokontroler ATMega 16 dengan Crystal 12 MHz. Untuk mengaktifkan Mikrokontroler ATMega 16 maka perlu diberikan tegangan catu daya + $5 \mathrm{~V}$ DC pada pin 30 dan pemberian tegangan nol (ground) pada pin 11. Disamping itu diperlukan juga pengaktifan osilator internal yang terdapat pada mikrokontroler ATMega 16. Untuk mengaktifkan osilator internal tersebut dalam perancangan ini digunakan kristal $12 \mathrm{MHz}$ untuk memperoleh kecepatan pelaksanaan instruksi per-siklus sebesar $12 \mathrm{MHz}$.

\subsubsection{Rangkaian LCD 4x20}

Pada rancangan alat ini menggunakan display LCD karakter 4x20, adapun rangkaian skematik LCD display ditunjukkan pada Gambar 4 dibawah ini. 


\section{Sumardi, Untara}

Shaking Water Bath Berbasis Mikrokontroler Atmega16

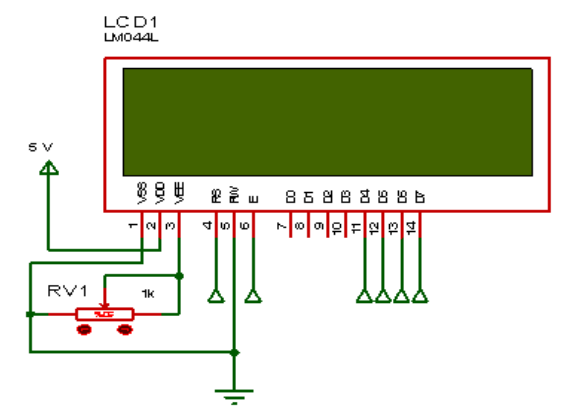

Gambar 4. Rangkaian LCD 4x20

LCD pada pembuatan alat ini digunakan untuk menampilkan hasil pengaturan yang dimasukan dan waktu proses alat beroperasi. LCD ini akan menampilkan display dikarenakan mendapatkan perintah sesuai dengan perintah program yang sudah ditanamkan pada mikrokontroler. Dengan memandang kebutuhan yang ada pada penelitian, maka digunakan LCD karakter yang berukuran 4x20 yang akan terhubung ke seluruh PORTC pada minimum sistem.

\subsubsection{Rangkaian Driver Valve}

Alat ini menggunakan rangkaian driver valve sebagai pengendali valve. Valve ini digunakan untuk membuang dan mengisi air pada chamber. Adapun rangkaian skematik driver valve ditunjukkan pada Gambar 5 dibawah ini.

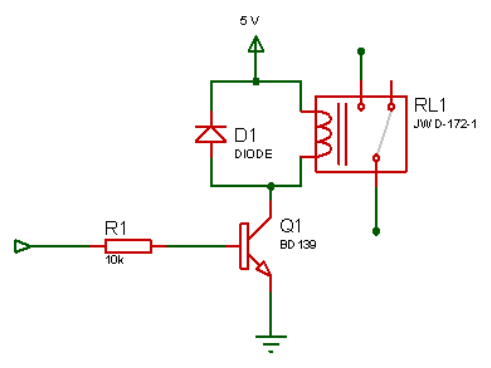

Gambar 5. Rangkaian driver valve

Prinsip kerja dari driver valve menggunakan relay sebagai saklar untuk memutus dan menyambung tegangan $12 \mathrm{~V} \mathrm{DC} \mathrm{(Direct} \mathrm{Current)} \mathrm{yang} \mathrm{akan} \mathrm{di-supply} \mathrm{ke} \mathrm{valve} 12 \mathrm{~V}$ DC. Selain menggunakan relay, pada rangkaian driver ini juga menggunakan transistor jenis NPN yang berfungsi untuk memutus dan menyambung ground yang akan diloloskan ke relay, sehingga relay bekerja bergantung pada transistor. Jika basis pada transistor mendapatkan tegangan $5 \mathrm{~V}$ DC dari kaki PD 1 atau PD 3 mikrokontroler melewati resistor 10 kiloohm maka ground akan diloloskan dari kaki kolektor ke emitor yang kemudian diteruskan ke relay sehingga relay bekerja. Ketika relay bekerja, tegangan $12 \mathrm{~V}$ DC akan diloloskan ke valve sehingga valve bekerja.

\subsubsection{Rangkaian Driver Heater}

Alat ini menggunakan rangkaian driver heater sebagai pengendali heater yang akan menghasilkan panas. Adapun rangkaian skematik driver heater ditunjukkan pada gambar 6.

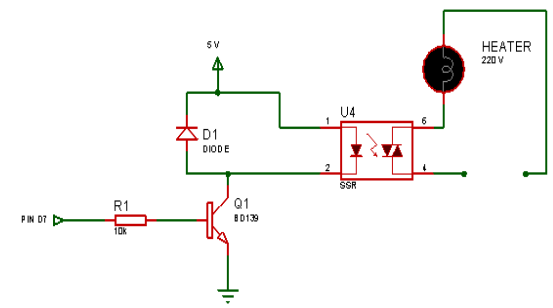

Gambar 6. Rangkaian driver heater

Medika Teknika : Jurnal Teknik Elektromedik Indonesia, Vol 02 No. 1, Oktober 2020|31 


\section{Sumardi, Untara}

Shaking Water Bath Berbasis Mikrokontroler Atmega16

Prinsip kerja dari driver heater menggunakan SSR (Solid State Relay) sebagai pensaklar untuk memutus dan menyambung tegangan $220 \mathrm{~V}$ AC (Alternating Current) yang akan di-supply ke heater. Selain menggunakan SSR, pada rangkaian driver ini juga menggunakan transistor NPN yang berfungsi untuk memutus dan menyambung ground yang akan diloloskan ke SSR, sehingga SSR bekerja bergantung pada transistor. Jika basis pada transistor mendapatkan tegangan 5 V DC (Direct Current) dari kaki PD 7 mikrokontroler melewati resistor 10 kiloohm maka ground akan diloloskan dari kaki kolektor ke emitor yang kemudian diteruskan ke SSR sehingga SSR bekerja. Ketika SSR bekerja, tegangan $220 \mathrm{~V}$ AC akan diloloskan ke heater sehingga heater bekerja.

\subsubsection{Rangkaian Driver Motor}

Alat ini menggunakan rangkaian driver motor sebagai pengontrol motor sebagai penggerak sistem shaking. Adapun rangkaian skematik driver motor ditunjukkan pada gambar 7.

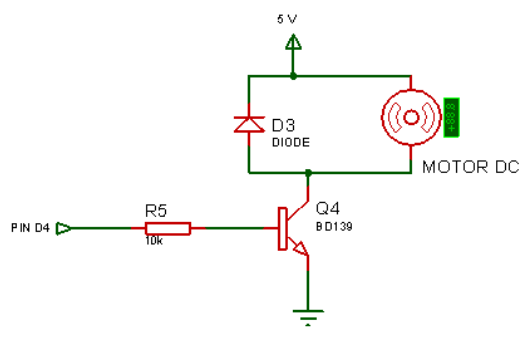

Gambar 7. Rangkaian driver motor

Prinsip kerja dari driver motor menggunakan transistor NPN yang berfungsi untuk memutus dan menyambung ground yang akan diloloskan ke motor, sehingga motor bekerja bergantung pada transistor. Jika basis pada transistor mendapatkan tegangan 5V DC (Direct Current) dari kaki PD 4 mikrokontroler melewati resistor 10 kiloohm maka ground akan diloloskan dari kaki kolektor ke emitor yang kemudian diteruskan ke motor sehingga motor bekerja.

\subsubsection{Rangkaian Driver Buzzer}

Alat ini dirancang dengan penambahan buzzer. Adapun rangkaian skematik dari buzzer ditunjukkan pada gambar 8 .

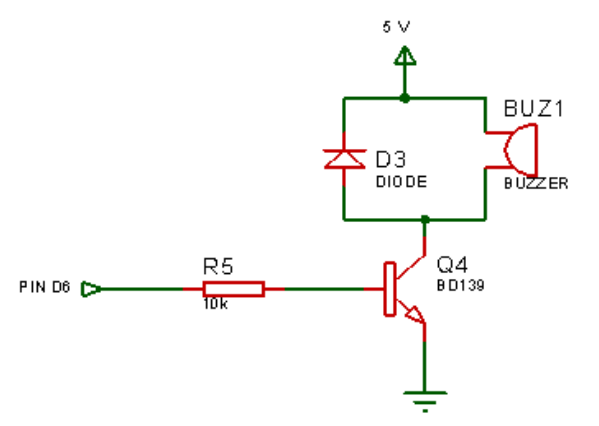

Gambar 8. Rangkaian Driver Buzzer

Prinsip kerja dari driver buzzer menggunakan transistor jenis NPN yang berfungsi untuk memutus dan menyambung ground yang akan diloloskan ke buzzer, sehingga buzzer bekerja bergantung pada transistor. Jika basis pada transistor mendapatkan tegangan 5V DC (Direct Current) dari kaki PD 6 mikrokontroler melewati resistor 10 kiloohm maka ground akan diloloskan dari kaki kolektor ke emitor yang kemudian diteruskan ke buzzer sehingga buzzer bekerja.

\subsection{Perancangan Software}

Shaking Water Bath tersusun dari beberapa rangkaian elektronik yang saling terintegrasi sehingga menciptakan suatu alat yang kompleks dan dapat berfungsi dengan baik. Adapun blok diagram yang digunakan untuk menciptakan alat Shaking Water Bath ini ditunjukkan pada gambar 9 dibawah ini.

Medika Teknika : Jurnal Teknik Elektromedik Indonesia, Vol 02 No. 1, Oktober 2020|32 


\section{Sumardi, Untara}

Shaking Water Bath Berbasis Mikrokontroler Atmega16

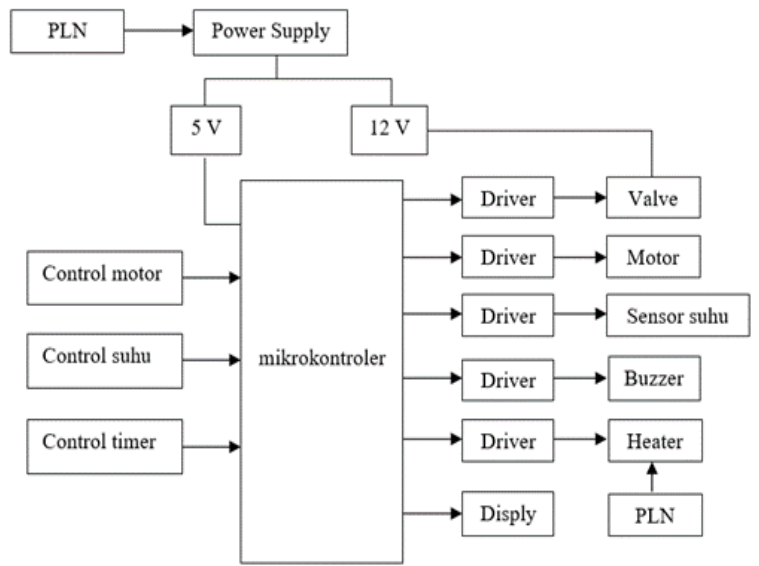

Gambar 9. Diagram Blok Sistem

Pada gambar 9 blok diagram diatas dapat diketahui cara kerja alat sebagai berikut, ketika tombol power ditekan ON maka tegangan PLN akan menyuplai ke power supply dan heater. Power supply kemudian menyuplai tegangan ke semua rangkaian. Kontrol motor digunakan untuk mengontrol kecepatan motor untuk menggoyang sampel larutan. Kontrol suhu digunakan untuk mengatur suhu air pada chamber water bath. Kontrol timer digunakan untuk mengatur lamanya waktu selama proses berlangsung. Semua hasil setting akan ditampilkan pada display LCD. Ketika timer habis maka motor akan berhenti bekerja, proses selesai dan buzzer berbunyi.

\subsection{Perancangan Desain Alat}

Desain bentuk alat yang dirancang oleh penulis ditunjukkan pada gambar 10 diagram mekanis dibawah ini.

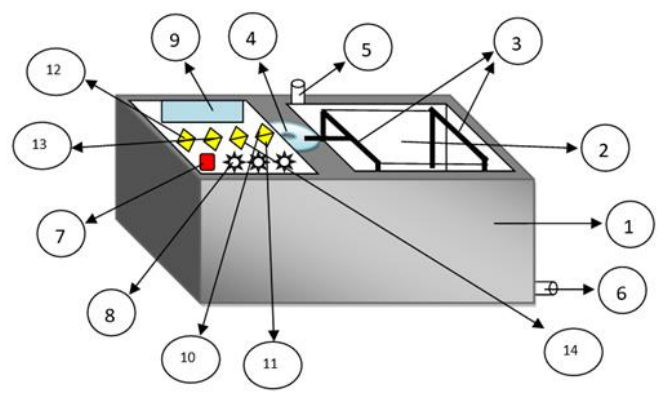

Gambar 10. Desain Alat Shaking Water Bath

Keterangan :

1. Body water bath

2. Chamber

3. Papan sampel (bisa bergerak ke kanan dan ke kiri)

4. Piringan motor, untuk menggerakkan papan sampel

5. Pipa air masuk

6. Pipa air keluar

7. Saklar power

8. Lampu indikator

9. Display LCD

Medika Teknika : Jurnal Teknik Elektromedik Indonesia, Vol 02 No. 1, Oktober 2020|33 


\section{Sumardi, Untara}

Shaking Water Bath Berbasis Mikrokontroler Atmega16

10. Tombol start

11. Tombol enter

12. Tombol up / down, untuk mengatur suhu

13. Tombol up / down, untuk mengatur timer/waktu

14. Tombol up / down, untuk mengatur shaking

\subsection{Pengambilan Data}

Metode pengujian dilakukan dengan cara membandingkan parameter timer dan suhu yang tertampil pada LCD alat yang dirancang, dengan stopwatch untuk parameter timer dan termometer untuk parameter suhu. Dari hasil yang diperoleh kemudian dihitung nilai rata-rata beserta nilai error.

\section{HASIL DAN PEMBAHASAN}

Berikut ini adalah data yang diperoleh dari pengukuran timer dan suhu dengan cara membandingkan parameter timer dan suhu yang tertampil pada LCD alat yang dirancang dengan stopwatch untuk parameter timer dan termometer untuk parameter suhu. Kemudian dari hasil yang didapat dihitung nilai rata-rata beserta nilai error.

\subsection{Hasil Pengukuran Parameter Timer 5 Menit (300 Detik)}

Pada tabel 1 berikut ini merupakan hasil pengukuran data dengan mengukur waktu selama 5 menit (300 detik) pada parameter timer dengan 20 kali pengukuran dengan alat pembanding stopwatch. Tujuan pengukuran ini untuk mengetahui nilai penyimpangan yang dihasilkan pada alat yang dirancang, sehingga dapat disimpulkan kelayakan alat yang dirancang yaitu alat tersebut layak atau tidak untuk digunakan. Nilai penyimpangan yang dicari adalah selisih antara hasil pembacaan pada alat yang dibuat dengan hasil pembacaan pada alat pembanding.

Tabel 1. Data Hasil Pengukuran Timer 5 Menit

\begin{tabular}{|c|c|c|c|}
\hline No & $\begin{array}{c}\text { Hasil pembacaan } \\
\text { Pada alat } \\
\end{array}$ & $\begin{array}{c}\text { Hasil pembacaan } \\
\text { pada stopwacth }\end{array}$ & Selisih \\
\hline 1 & 300 detik & 300 detik & O detik \\
\hline 2 & 300 detik & 300 detik & O detik \\
\hline 3 & 300 detik & 300 detik & $O$ detik \\
\hline 4 & 300 detik & 300 detik & O detik \\
\hline 5 & 300 detik & 300 detik & O detik \\
\hline 6 & 300 detik & 300 detik & O detik \\
\hline 7 & 300 detik & 299 detik & 1 detik \\
\hline 8 & 300 detik & 300 detik & $O$ detik \\
\hline 9 & 300 detik & 300 detik & O detik \\
\hline 10 & 300 detik & 300 detik & O detik \\
\hline 11 & 300 detik & 300 detik & O detik \\
\hline 12 & 300 detik & 300 detik & O detik \\
\hline 13 & 300 detik & 300 detik & O detik \\
\hline 14 & 300 detik & 299 detik & 1 detik \\
\hline 15 & 300 detik & 301 detik & 1 detik \\
\hline 16 & 300 detik & 300 detik & $O$ detik \\
\hline 17 & 300 detik & 300 detik & O detik \\
\hline 18 & 300 detik & 300 detik & O detik \\
\hline 19 & 300 detik & 300 detik & $O$ detik \\
\hline 20 & 300 detik & 300 detik & O detik \\
\hline \multicolumn{2}{|c|}{ Rata-rata (detik ) } & 299,95 detik & \\
\hline \multirow{2}{*}{\multicolumn{2}{|c|}{ Simpangan }} & \multirow{2}{*}{\multicolumn{2}{|c|}{$-0,05 \%$}} \\
\hline & & & \\
\hline
\end{tabular}

Dari tabel 1 hasil pengukuran timer dengan pengaturan waktu 300 detik, didapat hasil ratarata 299,95 detik dan error sebesar 0,02\%. Penyimpangan terbesar pada saat pengambilan data ke7, ke-14, dan ke-15 yaitu sebesar 1 detik. Penyimpangan yang terjadi karena kesalahan saat memulai atau menekan start secara bersamaan antara alat yang diusulkan dengan alat ukur pembanding.

\subsection{Hasil Pengukuran Parameter Timer 10 Menit (600 Detik)}

Pada tabel 2 berikut ini merupakan hasil pengukuran data dengan mengukur waktu selama 10 menit (600 detik) pada parameter timer dengan 20 kali pengukuran dengan alat pembanding stopwatch. Tujuan pengukuran ini untuk mengetahui nilai penyimpangan yang dihasilkan pada alat 


\section{Sumardi, Untara}

Shaking Water Bath Berbasis Mikrokontroler Atmega16

yang dirancang, sehingga dapat disimpulkan kelayakan alat yang dirancang, yaitu layak atau tidak untuk digunakan.

Tabel 2. Data Hasil Pengukuran Timer 10 Menit

\begin{tabular}{|c|c|c|c|}
\hline No & $\begin{array}{c}\text { Hasil pembacaan } \\
\text { Pada alat }\end{array}$ & \begin{tabular}{|c|} 
Hasil pembacaan \\
pada stopwacth
\end{tabular} & Selisih \\
\hline 1 & 600 detik & 599 detik & 1 detik \\
\hline 2 & 600 detik & 599 detik & 1 detik \\
\hline 3 & 600 detik & 599 detik & 1 detik \\
\hline 4 & 600 detik & 599 detik & 1 detik \\
\hline 5 & 600 detik & 599 detik & 1 detik \\
\hline 6 & 600 detik & 599 detik & 1 detik \\
\hline 7 & 600 detik & 599 detik & 1 detik \\
\hline 8 & 600 detik & 599 detik & 1 detik \\
\hline 9 & 600 detik & 599 detik & 1 detik \\
\hline 10 & 600 detik & 599 detik & 1 detik \\
\hline 11 & 600 detik & 599 detik & 1 detik \\
\hline 12 & 600 detik & 598 detik & 2 detik \\
\hline 13 & 600 detik & 598 detik & 2 detik \\
\hline 14 & 600 detik & 598 detik & 2 detik \\
\hline 15 & 600 detik & 599 detik & 1 detik \\
\hline 16 & 600 detik & 598 detik & 2 detik \\
\hline 17 & 600 detik & 598 detik & 2 detik \\
\hline 18 & 600 detik & 598 detik & 2 detik \\
\hline 19 & 600 detik & 599 detik & 1 detik \\
\hline 20 & 600 detik & 599 detik & 1 detik \\
\hline \multicolumn{2}{|c|}{ Rata-rata ( detik ) } & \multicolumn{2}{|l|}{598,7 detik } \\
\hline \multicolumn{2}{|r|}{ Simpangan } & \multicolumn{2}{|l|}{$1,30 \%$} \\
\hline \multicolumn{2}{|r|}{ Eror } & \multicolumn{2}{|l|}{$0,22 \%$} \\
\hline
\end{tabular}

Dari tabel 2 hasil pengukuran timer dengan pengaturan waktu 600 detik, didapat hasil ratarata 598,70 detik dan error sebesar 0,22\%. Penyimpangan terbesar pada saat pengambilan data ke12, ke-13, ke-14, ke-16, ke-17 dan ke-18 yaitu sebesar 2 detik. Penyimpangan yang terjadi karena kesalahan saat memulai atau menekan start secara bersamaan antara alat yang diusulkan dengan alat ukur pembanding.

\subsection{Hasil Pengukuran Parameter Timer 15 Menit (900 Detik)}

Pada tabel 3 berikut ini merupakan hasil pengukuran data dengan mengukur waktu selama 15 menit (900 detik) pada parameter timer dengan 20 kali pengukuran dengan alat pembanding stopwatch. Tujuan pengukuran ini untuk mengetahui nilai penyimpangan yang dihasilkan pada alat yang dibuat, sehingga dapat disimpulkan bahwa alat yang dirancang layak atau tidak untuk digunakan. Nilai penyimpangan yang dicari adalah selisih antara hasil pembacaan pada alat yang dirancang dengan hasil pembacaan pada alat pembanding.

Tabel 3. Data Hasil Pengukuran Timer 15 Menit

\begin{tabular}{|c|c|c|c|}
\hline No & $\begin{array}{c}\text { Hasil pembacaan } \\
\text { Pada alat }\end{array}$ & $\begin{array}{c}\text { Hasil pembacaan } \\
\text { pada stopwacth }\end{array}$ & Selisih \\
\hline 1 & 900 detik & 899 detik & 1 detik \\
\hline 2 & 900 detik & 899 detik & 1 detik \\
\hline 3 & 900 detik & 899 detik & 1 detik \\
\hline 4 & 900 detik & 899 detik & 1 detik \\
\hline 5 & 900 detik & 899 detik & 1 detik \\
\hline 6 & 900 detik & 899 detik & 1 detik \\
\hline 7 & 900 detik & 899 detik & 1 detik \\
\hline 8 & 900 detik & 899 detik & 1 detik \\
\hline 9 & 900 detik & 899 detik & 1 detik \\
\hline 10 & 900 detik & 899 detik & 1 detik \\
\hline 11 & 900 detik & 899 detik & 1 detik \\
\hline 12 & 900 detik & 898 detik & 2 detik \\
\hline 13 & 900 detik & 899 detik & 1 detik \\
\hline 14 & 900 detik & 899 detik & 1 detik \\
\hline 15 & 900 detik & 899 detik & 1 detik \\
\hline 16 & 900 detik & 898 detik & 2 detik \\
\hline 17 & 900 detik & 899 detik & 1 detik \\
\hline 18 & 900 detik & 898 detik & 2 detik \\
\hline 19 & 900 detik & 898 detik & 2 detik \\
\hline 20 & 900 detik & 899 detik & 1 detik \\
\hline \multicolumn{2}{|r|}{ Rata-rata ( detik $)$} & $\mathbf{8 9 8 , 8 ~ d e t i k ~}$ & \\
\hline & Simpangan & $\mathbf{1 , 2 0 \%}$ & $\mathbf{0 , 1 3 \%}$ \\
\hline & Eror & & \\
\hline
\end{tabular}




\section{Sumardi, Untara}

Shaking Water Bath Berbasis Mikrokontroler Atmega16

Dari tabel 3 hasil pengukuran timer dengan pengaturan waktu 900 detik, didapat hasil ratarata 898,80 detik. Penyimpangan terbesar pada saat pengambilan data ke-12, ke-16, ke-18, dan ke19 yaitu sebesar 2 detik. Penyimpangan yang terjadi karena kesalahan saat memulai atau menekan tombol start secara bersamaan antara alat penelitian dengan alat ukur pembanding.

\subsection{Hasil Pengukuran Parameter Suhu $37^{\circ} \mathrm{C}$}

Pada tabel 4 berikut ini merupakan hasil pengukuran data dengan mengukur suhu air dalam bak atau chamber pada parameter suhu $37{ }^{\circ} \mathrm{C}$ dengan 20 kali pengukuran dengan alat pembanding termometer suhu yang telah dikalibrasi. Tujuan pengukuran ini untuk mengetahui nilai penyimpangan yang dihasilkan pada alat yang dirancang, sehingga dapat disimpulkan bahwa alat yang dirancang layak atau tidak untuk digunakan. Nilai penyimpangan yang dicari adalah selisih antara hasil pembacaan pada alat yang dibuat dengan hasil pembacaan pada alat pembanding.

Dari Tabel 4 hasil pengukuran suhu dengan pengaturan suhu $37 \mathrm{oC}$, didapat suhu hasil ratarata $37,4 \mathrm{oC}$ dan nilai error sebesar $0,92 \%$. Penyimpangan terbesar pada saat pengambilan data ke14 dengan suhu 0,6 oC dan pengukuran ke-15 yaitu pada suhu 0,5 oC. Penyimpangan yang terjadi masih dalam batas toleransi, karena suhu hasil perhitungan masih dibawah $1 \mathrm{oC}$.

Tabel 4. Data Hasil Pengukuran Suhu $37^{\circ} \mathrm{C}$

\begin{tabular}{|c|c|c|c|}
\hline No & $\begin{array}{c}\text { Hasil pembacaan } \\
\text { Pada alat }\end{array}$ & \begin{tabular}{|l|} 
Hasil pembacaan \\
pada termometer
\end{tabular} & Selisih \\
\hline 1 & $37,1^{\circ} \mathrm{C}$ & $37,2{ }^{\circ} \mathrm{C}$ & $0,1^{\circ} \mathrm{C}$ \\
\hline 2 & $37,1^{\circ} \mathrm{C}$ & $37,2^{\circ} \mathrm{C}$ & $0,1{ }^{\circ} \mathrm{C}$ \\
\hline 3 & $37,6^{\circ} \mathrm{C}$ & $37,4^{\circ} \mathrm{C}$ & $0,2{ }^{\circ} \mathrm{C}$ \\
\hline 4 & $37,6^{\circ} \mathrm{C}$ & $37,4^{\circ} \mathrm{C}$ & $0,2{ }^{\circ} \mathrm{C}$ \\
\hline 5 & $37,1^{\circ} \mathrm{C}$ & $37,2{ }^{\circ} \mathrm{C}$ & $0,1^{\circ} \mathrm{C}$ \\
\hline 6 & $37,1^{\circ} \mathrm{C}$ & $37,4^{\circ} \mathrm{C}$ & $0,3{ }^{\circ} \mathrm{C}$ \\
\hline 7 & $37,1^{\circ} \mathrm{C}$ & $37,4^{\circ} \mathrm{C}$ & $0,3{ }^{\circ} \mathrm{C}$ \\
\hline 8 & $37,1^{\circ} \mathrm{C}$ & $37,1^{\circ} \mathrm{C}$ & $\mathrm{O}^{\circ} \mathrm{C}$ \\
\hline 9 & $37,1^{\circ} \mathrm{C}$ & $37,2{ }^{\circ} \mathrm{C}$ & $0,1{ }^{\circ} \mathrm{C}$ \\
\hline 10 & $37,1^{\circ} \mathrm{C}$ & $37,4^{\circ} \mathrm{C}$ & $0,3{ }^{\circ} \mathrm{C}$ \\
\hline 11 & $37,6^{\circ} \mathrm{C}$ & $37,6^{\circ} \mathrm{C}$ & $\mathrm{O}^{\circ} \mathrm{C}$ \\
\hline 12 & $37,6^{\circ} \mathrm{C}$ & $37,4^{\circ} \mathrm{C}$ & $0,2{ }^{\circ} \mathrm{C}$ \\
\hline 13 & $37,6^{\circ} \mathrm{C}$ & $37,8^{\circ} \mathrm{C}$ & $0,2{ }^{\circ} \mathrm{C}$ \\
\hline 14 & $37,6^{\circ} \mathrm{C}$ & $38,2{ }^{\circ} \mathrm{C}$ & $0,6{ }^{\circ} \mathrm{C}$ \\
\hline 15 & $37,1^{\circ} \mathrm{C}$ & $37,6^{\circ} \mathrm{C}$ & $0,5^{\circ} \mathrm{C}$ \\
\hline 16 & $37,1^{\circ} \mathrm{C}$ & $37,4^{\circ} \mathrm{C}$ & $0,3^{\circ} \mathrm{C}$ \\
\hline 17 & $37,6{ }^{\circ} \mathrm{C}$ & $37,7^{\circ} \mathrm{C}$ & $0,1{ }^{\circ} \mathrm{C}$ \\
\hline 18 & $37,6^{\circ} \mathrm{C}$ & $37,6^{\circ} \mathrm{C}$ & $\mathrm{O}^{\circ} \mathrm{C}$ \\
\hline 19 & $37,1^{\circ} \mathrm{C}$ & $37,2^{\circ} \mathrm{C}$ & $0,1^{\circ} \mathrm{C}$ \\
\hline 20 & $37,1^{\circ} \mathrm{C}$ & $37,4^{\circ} \mathrm{C}$ & $0,3{ }^{\circ} \mathrm{C}$ \\
\hline \multicolumn{2}{|c|}{ Rata-rata $\left({ }^{\circ} \mathrm{C}\right)$} & \multicolumn{2}{|l|}{$37,44^{\circ} \mathrm{C}$} \\
\hline \multicolumn{2}{|r|}{ Simpangan } & \multicolumn{2}{|l|}{$0,34 \%$} \\
\hline \multicolumn{2}{|r|}{ Eror } & \multicolumn{2}{|l|}{$0,92 \%$} \\
\hline
\end{tabular}

\subsection{Hasil Pengukuran Parameter Suhu $45^{\circ} \mathrm{C}$}

Pada tabel 5 berikut ini merupakan hasil pengukuran data dengan mengukur suhu air dalam bak atau chamber pada parameter suhu $45{ }^{\circ} \mathrm{C}$ dengan 20 kali pengukuran dengan alat pembanding termometer suhu yang sudah dikalibrasi. Tujuan pengukuran ini untuk mengetahui nilai penyimpangan yang dihasilkan pada alat yang dirancang, sehingga dapat disimpulkan bahwa alat yang dirancang layak atau tidak untuk digunakan. Nilai penyimpangan yang dicari adalah selisih antara hasil pembacaan pada alat yang dirancang dengan hasil pembacaan pada alat pembanding. 


\section{Sumardi, Untara}

Shaking Water Bath Berbasis Mikrokontroler Atmega16

Tabel 5. Data Hasil Pengukuran Suhu $45^{\circ} \mathrm{C}$

\begin{tabular}{|c|c|c|c|}
\hline No & $\begin{array}{c}\text { Hasil pembacaan } \\
\text { Pada alat }\end{array}$ & $\begin{array}{l}\text { Hasil pembacaan } \\
\text { pada termometer }\end{array}$ & Selisih \\
\hline 1 & $45,4^{\circ} \mathrm{C}$ & $45,1^{\circ} \mathrm{C}$ & $0,3{ }^{\circ} \mathrm{C}$ \\
\hline 2 & $45,9^{\circ} \mathrm{C}$ & $46,3^{\circ} \mathrm{C}$ & $0,4^{\circ} \mathrm{C}$ \\
\hline 3 & $45,9^{\circ} \mathrm{C}$ & $46,2{ }^{\circ} \mathrm{C}$ & $0,3{ }^{\circ} \mathrm{C}$ \\
\hline 4 & $45,9^{\circ} \mathrm{C}$ & $46,2{ }^{\circ} \mathrm{C}$ & $0,3{ }^{\circ} \mathrm{C}$ \\
\hline 5 & $45,9^{\circ} \mathrm{C}$ & $46,0^{\circ} \mathrm{C}$ & $\mathrm{O}, 1^{\circ} \mathrm{C}$ \\
\hline 6 & $45,4^{\circ} \mathrm{C}$ & $45,1^{\circ} \mathrm{C}$ & $0,3^{\circ} \mathrm{C}$ \\
\hline 7 & $45,4^{\circ} \mathrm{C}$ & $45,3^{\circ} \mathrm{C}$ & $0,1{ }^{\circ} \mathrm{C}$ \\
\hline 8 & $45,4^{\circ} \mathrm{C}$ & $45,3^{\circ} \mathrm{C}$ & $0,1{ }^{\circ} \mathrm{C}$ \\
\hline 9 & $45,4^{\circ} \mathrm{C}$ & $45,2{ }^{\circ} \mathrm{C}$ & $0,2{ }^{\circ} \mathrm{C}$ \\
\hline 10 & $45,4^{\circ} \mathrm{C}$ & $45,3^{\circ} \mathrm{C}$ & $\mathrm{O}, 1{ }^{\circ} \mathrm{C}$ \\
\hline 11 & $45,4^{\circ} \mathrm{C}$ & $45,1^{\circ} \mathrm{C}$ & $0,3{ }^{\circ} \mathrm{C}$ \\
\hline 12 & $45,4^{\circ} \mathrm{C}$ & $45,5^{\circ} \mathrm{C}$ & $0,1^{\circ} \mathrm{C}$ \\
\hline 13 & $45,4^{\circ} \mathrm{C}$ & $45,3^{\circ} \mathrm{C}$ & $0,1^{\circ} \mathrm{C}$ \\
\hline 14 & $45,9^{\circ} \mathrm{C}$ & $46,4^{\circ} \mathrm{C}$ & $0,5^{\circ} \mathrm{C}$ \\
\hline 15 & $45,9^{\circ} \mathrm{C}$ & $46,2^{\circ} \mathrm{C}$ & $0,3^{\circ} \mathrm{C}$ \\
\hline 16 & $45,9^{\circ} \mathrm{C}$ & $45,9^{\circ} \mathrm{C}$ & $\mathrm{O}^{\circ} \mathrm{C}$ \\
\hline 17 & $45,4^{\circ} \mathrm{C}$ & $45,5^{\circ} \mathrm{C}$ & $0,1{ }^{\circ} \mathrm{C}$ \\
\hline 18 & $45,4^{\circ} \mathrm{C}$ & $45,4^{\circ} \mathrm{C}$ & $\mathrm{O}^{\circ} \mathrm{C}$ \\
\hline 19 & $45,4^{\circ} \mathrm{C}$ & $45,2{ }^{\circ} \mathrm{C}$ & $0,2{ }^{\circ} \mathrm{C}$ \\
\hline 20 & $45,4^{\circ} \mathrm{C}$ & $45,3^{\circ} \mathrm{C}$ & $\mathrm{O}, 1{ }^{\circ} \mathrm{C}$ \\
\hline \multicolumn{2}{|c|}{ Rata-rata $\left({ }^{\circ} \mathrm{C}\right)$} & \multicolumn{2}{|l|}{$45,59^{\circ} \mathrm{C}$} \\
\hline \multicolumn{2}{|r|}{ Simpangan } & \multicolumn{2}{|l|}{$0,39 \%$} \\
\hline \multicolumn{2}{|r|}{ Eror } & \multicolumn{2}{|l|}{$0,86 \%$} \\
\hline
\end{tabular}

Dari tabel 5 hasil pengukuran suhu dengan pengaturan suhu $45{ }^{\circ} \mathrm{C}$, didapat hasil suhu ratarata $45,59{ }^{\circ} \mathrm{C}$ dan nilai error sebesar $0,86 \%$. Penyimpangan terbesar pada saat pengambilan data ke-2 suhu terukur $0,4{ }^{\circ} \mathrm{C}$ dan pengukuran ke-14 yaitu suhu terukur $0,5{ }^{\circ} \mathrm{C}$. Penyimpangan yang terjadi masih dalam batas toleransi, karena suhu hasil perhitungan masih dibawah $1{ }^{\circ} \mathrm{C}$.

\subsection{Hasil Pengukuran Parameter suhu $55^{\circ} \mathrm{C}$}

Pada tabel 6 berikut ini merupakan hasil pengukuran data dengan mengukur suhu air dalam bak (chamber) pada parameter suhu $55{ }^{\circ} \mathrm{C}$ dengan 20 kali pengukuran dengan alat pembanding termometer suhu yang telah dikalibrasi. Tujuan pengukuran ini untuk mengetahui nilai penyimpangan yang dihasilkan pada alat yang dirancang, sehingga dapat disimpulkan bahwa alat yang dirancang layak atau tidak untuk digunakan.

Tabel 6. Data Hasil Pengukuran Suhu $37^{\circ} \mathrm{C}$

\begin{tabular}{|c|c|c|c|}
\hline No & $\begin{array}{c}\text { Hasil pembacaan } \\
\text { Pada alat }\end{array}$ & \begin{tabular}{|l|} 
Hasil pembacaan \\
pada termometer
\end{tabular} & Selisih \\
\hline 1 & $55,2^{\circ} \mathrm{C}$ & $55,5^{\circ} \mathrm{C}$ & $0,3^{\circ} \mathrm{C}$ \\
\hline 2 & $55,2^{\circ} \mathrm{C}$ & $55,3^{\circ} \mathrm{C}$ & $\mathrm{O}, 1^{\circ} \mathrm{C}$ \\
\hline 3 & $55,2^{\circ} \mathrm{C}$ & $55,5^{\circ} \mathrm{C}$ & $0,3^{\circ} \mathrm{C}$ \\
\hline 4 & $55,2^{\circ} \mathrm{C}$ & $55,2^{\circ} \mathrm{C}$ & $\mathrm{O}^{\circ} \mathrm{C}$ \\
\hline 5 & $55,2^{\circ} \mathrm{C}$ & $55,4^{\circ} \mathrm{C}$ & $0,2^{\circ} \mathrm{C}$ \\
\hline 6 & $55,2^{\circ} \mathrm{C}$ & $55,4^{\circ} \mathrm{C}$ & $0,2^{\circ} \mathrm{C}$ \\
\hline 7 & $55,2^{\circ} \mathrm{C}$ & $55,5^{\circ} \mathrm{C}$ & $0,3^{\circ} \mathrm{C}$ \\
\hline 8 & $55,2^{\circ} \mathrm{C}$ & $55,4^{\circ} \mathrm{C}$ & $0,2^{\circ} \mathrm{C}$ \\
\hline 9 & $55,2^{\circ} \mathrm{C}$ & $55,2^{\circ} \mathrm{C}$ & $\mathrm{O}^{\circ} \mathrm{C}$ \\
\hline 10 & $55,2^{\circ} \mathrm{C}$ & $55,5^{\circ} \mathrm{C}$ & $0,3^{\circ} \mathrm{C}$ \\
\hline 11 & $55,7^{\circ} \mathrm{C}$ & $55,5^{\circ} \mathrm{C}$ & $0,2^{\circ} \mathrm{C}$ \\
\hline 12 & $55,2^{\circ} \mathrm{C}$ & $55,6^{\circ} \mathrm{C}$ & $0,4^{\circ} \mathrm{C}$ \\
\hline 13 & $55,2^{\circ} \mathrm{C}$ & $55,4^{\circ} \mathrm{C}$ & $0,2^{\circ} \mathrm{C}$ \\
\hline 14 & $55,2^{\circ} \mathrm{C}$ & $55,6^{\circ} \mathrm{C}$ & $0,4^{\circ} \mathrm{C}$ \\
\hline 15 & $55,2^{\circ} \mathrm{C}$ & $55,3^{\circ} \mathrm{C}$ & $0,1^{\circ} \mathrm{C}$ \\
\hline 16 & $55,2^{\circ} \mathrm{C}$ & $55,2^{\circ} \mathrm{C}$ & $\mathrm{O}^{\circ} \mathrm{C}$ \\
\hline 17 & $55,2^{\circ} \mathrm{C}$ & $55,4^{\circ} \mathrm{C}$ & $0,2^{\circ} \mathrm{C}$ \\
\hline 18 & $55,7^{\circ} \mathrm{C}$ & $55,6^{\circ} \mathrm{C}$ & $0,1^{\circ} \mathrm{C}$ \\
\hline 19 & $55,2^{\circ} \mathrm{C}$ & $55,5^{\circ} \mathrm{C}$ & $0,3^{\circ} \mathrm{C}$ \\
\hline 20 & $55,7^{\circ} \mathrm{C}$ & $55,2^{\circ} \mathrm{C}$ & $0,5^{\circ} \mathrm{C}$ \\
\hline \multicolumn{2}{|c|}{ Rata-rata $\left({ }^{\circ} \mathrm{C}\right)$} & \multicolumn{2}{|l|}{$55,41{ }^{\circ} \mathrm{C}$} \\
\hline \multicolumn{2}{|r|}{ Simpangan } & \multicolumn{2}{|l|}{$0,21 \%$} \\
\hline \multicolumn{2}{|r|}{ Eror } & \multicolumn{2}{|l|}{$0,38 \%$} \\
\hline
\end{tabular}




\section{Sumardi, Untara}

Shaking Water Bath Berbasis Mikrokontroler Atmega16

Dari tabel 6 hasil pengukuran suhu dengan pengaturan suhu $55{ }^{\circ} \mathrm{C}$, didapat hasil rata-rata $55,41{ }^{\circ} \mathrm{C}$ dan nilai error sebesar $0,38 \%$. Penyimpangan terbesar pada saat pengambilan data ke-12 dan pengukuran ke-14 suhu terukur $0,4{ }^{\circ} \mathrm{C}$ serta pengukuran ke-20 yaitu sebesar $0,5{ }^{\circ} \mathrm{C}$. Penyimpangan yang terjadi masih dalam batas toleransi, karena suhu hasil perhitungan masih dibawah $1{ }^{\circ} \mathrm{C}$.

\subsection{Hasil Pengujian Shaking}

Pengujian ini bertujuan untuk mengetahui apakah shaking ini bisa berfungsi untuk mencampur larutan sampel atau tidak. Sampel bahan yang akan digunakan untuk pengujian ini adalah bahan yang bisa larut ke dalam air, antara lain gula pasir, kopi bubuk, dan sabun cuci tangan cair. Kemudian dicatat waktu yang dibutuhkan bahan tersebut tercampur ke dalam air.
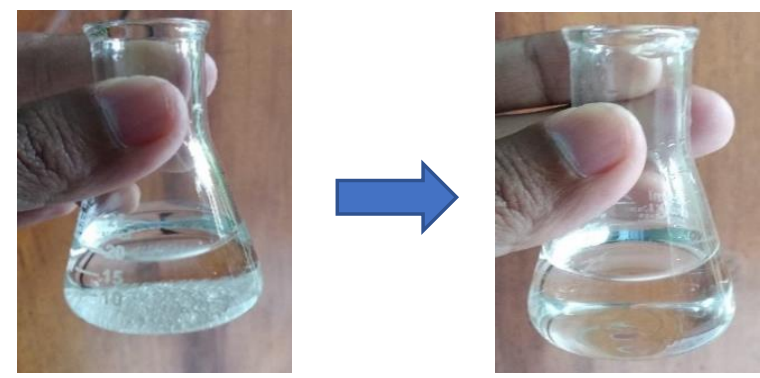

Gambar 11. Hasil Pengujian Shaking Dengan Bahan Gula Pasir dan Air

Dari Gambar 11 hasil pengujian shaking atau pencampuran dengan bahan gula pasir dengan komposisi $20 \mathrm{ml}$ air dan 2 gram gula pasir didapat bahwa waktu tercepat pada level kecepatan level 3 , dimana waktu yang dibutuhkan untuk mencampur gula pasir adalah 5 menit. Kecepatan level 2 membutuhkan waktu 10 menit untuk mencampur gula pasir dan kecepatan level 1 butuh waktu lebih lama dari level 2 dan level 3 yaitu selama 20 menit.
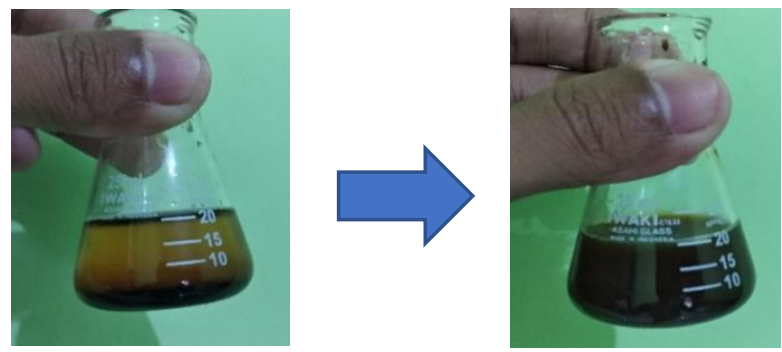

Gambar 12. Hasil Pengujian Shaking Dengan Bahan Kopi Bubuk dan Air

Dari gambar 12 hasil pengujian shaking atau pencampuran dengan bahan kopi bubuk dengan komposisi $20 \mathrm{ml}$ air dan 2 gram kopi didapat bahwa waktu tercepat pada level kecepatan level 3, dimana waktu yang dibutuhkan untuk mencampur kopi adalah 3 menit. Kecepatan level 2 membutuhkan waktu 5 menit untuk mencampur kopi dan kecepatan level 1 butuh waktu lebih lama dari level 2 dan level 3 yaitu selama 8 menit.
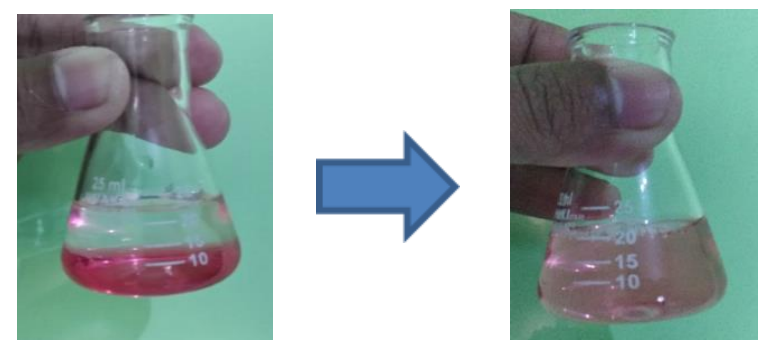

Medika Teknika : Jurnal Teknik Elektromedik Indonesia, Vol 02 No. 1, Oktober 2020|38 


\section{Sumardi, Untara}

Shaking Water Bath Berbasis Mikrokontroler Atmega16

\section{Gambar 13. Hasil Pengujian Shaking Dengan Bahan Sabun Cuci Tangan dan Air}

Dari gambar 13 hasil pengujian shaking atau pencampuran dengan bahan sabun cuci tangan dengan komposisi $20 \mathrm{ml}$ air dan $2 \mathrm{ml}$ sabun cuci tangan didapat bahwa waktu tercepat pada level kecepatan level 3, dimana waktu yang dibutuhkan untuk mencampur sabun cuci tangan adalah 1 menit. Kecepatan level 2 membutuhkan waktu 2 menit untuk mencampur sabun cuci tangan dan kecepatan level 1 butuh waktu lebih lama dari level 2 dan level 3 yaitu selama 4 menit.

Dari hasil pengujian shaking diatas didapat bahwa pada pengujian pencampuran gula pasir dengan level kecepatan level 1 dibutuhkan waktu 20 menit, level 2 dibutuhkan waktu 12 menit, dan level 3 dibutuhkan waktu 5 menit. Pada pengujian pencampuran kopi bubuk level kecepatan level 1 dibutuhkan waktu 8 menit, level 2 dibutuhkan waktu 5 menit, dan level 3 dibutuhkan waktu 3 menit. Pada pengujian pencampuran sabun cuci tangan dengan level kecepatan level 1 dibutuhkan waktu 4 menit, level 2 dibutuhkan waktu 2 menit, dan pada level 3 dibutuhkan waktu 1 menit. Dari pengujian tersebut dapat disimpulkan bahwa semakin tinggi level kecepatan yang digunakan, maka semakin cepat waktu yang dibutuhkan bahan tersebut bisa tercampur ke dalam air.

\section{KESIMPULAN}

Setelah melakukan penelitian ini, penulis dapat menyimpulkan beberapa hal terkait hasil penelitian yang telah dilakukan, yaitu sebagai berikut:

Dari hasil pengujian timer didapat nilai penyimpangan yang kecil dari alat pembanding yang digunakan. Penyimpangan yang didapat yaitu sebesar 0,5 detik dari nilai rata-rata pada pengujian timer 5 menit, penyimpangan sebesar 1 detik dari nilai rata-rata pada pengujian timer 10 menit dan 15 menit.

Dari hasil pengujian suhu didapat nilai penyimpangan yang relatif kecil dari alat pembanding yang digunakan. Penyimpangan yang didapat yaitu sebesar $0,44{ }^{\circ} \mathrm{C}$ dari nilai rata-rata pada pengujian suhu $37{ }^{\circ} \mathrm{C}$, penyimpangan sebesar $0,59{ }^{\circ} \mathrm{C}$ dari nilai rata-rata pada pengujian suhu 45 ${ }^{\circ} \mathrm{C}$, dan penyimpangan sebesar $0,41^{\circ} \mathrm{C}$ dari nilai rata-rata pada pengujian suhu $55^{\circ} \mathrm{C}$.

Dari hasil pengujian shaking dapat disimpulkan bahwa alat yang dibuat dapat melakukan pencampuran antara 2 jenis zat yang dapat larut kedalam air. Semakin tinggi level kecepatan yang digunakan maka waktu yang dibutuhkan untuk pencampuran akan semakin sedikit atau semakin cepat zat tersebut tercampur.

\section{DAFTAR PUSTAKA}

[1] "Hematologi Dan Perannya Dalam Menangani Gangguan Darah 2." [Online]. Available: https://www.alodokter.com/hematologi-dan-perannya-dalam-menangani-gangguan-darah-2. [Accessed: 05-Oct-2019].

[2] A. M. Sholihati and M. Baharuddin, "PRODUKSI DAN UJI AKTIVITAS ENZIM SELULASE DARI BAKTERI Bacillus subtilis," Jur. Kim. UIN Makasar Prodi Anakes STIKes Mega Risky Makasar, pp. 78-90, 2014.

[3] R. Khairani and I. Taufiq, "Rancang-Bangun Sistem Kontrol Solution Shaker Berbasis Mikrokontroller AT89S51 Dengan Motor Steper Sebagai Penggerak," J. ILMU Fis. (JIF), VOL 7 NO 1, MARET 2015, vol. 7, no. 1, pp. 7-13, 2015.

[4] A. A. AMZAILI, "Waterbath Menggunakan Valve Berbasi Mikrokontroler Atmega 16," 2016.

[5] A. Prihartono, D. Larassati, B. Herlambang, and A. Insani, "Perancangan Dan Pembuatan Sistem Otomatis Water Bath Untuk Kalibrasi Suhu," J. Fis. Unand Vol. 5, No. 1, vol. 5, pp. $1-5,2016$.

[6] K. Husni, W. Wildian, and M. Yusfi, "Rancang Bangun Shaking Water Bath Berbasis Mikrokontroler ATmega16," J. Fis. Unand, vol. 6, no. 1, pp. 9-16, 2017.

[7] I. S. SAPUTRO, "Rancang Bangun Inkubator Shaker Berbasis Arduino Uno R3," Jerusan Teknik Elektromedik Poltekes Kemenkes Jakarta II, 2018. . 